\title{
Pintura mural como experiência educacional em uma oficina de arte educação ${ }^{1}$
}

\author{
Mariete Taschetto Uberti ${ }^{2}$
}

\begin{abstract}
Resumo: Este artigo resulta de uma pesquisa qualitativa que objetivou contextualizar as possibilidades da pintura mural numa proposição educativa em artes, por meio de uma oficina de arte mural, com um grupo de jovens da Escola Aberta, na Escola Estadual de Educação Básica Augusto Ruschi, em Santa Maria, RS. Tal premissa foi pensada e embasada pelo estudo da pintura mural e suas confluências com a arte e o espaço, enquanto subsídio que possibilitasse experiências em artes junto aos educandos, através de entrelaçamentos com a educação na contemporaneidade, a arte, a pintura e o cotidiano destes jovens.
\end{abstract}

Palavras Chaves: Pintura mural; Educação em Artes Visuais; Cotidiano.

Abstract: This article is a result of a qualitative research that aimed to contextualize the possibilities of the painting mural in an educational proposition in arts, through a workshop of mural art with a group of youths from the Open School, in the State School of Basic Education Augusto Ruschi, in Santa Maria, RS. Such premise was thought and based by the study of painting mural and its confluence with art and space, while subsidy that has enabled experiences in arts close to students, through interlacements with education in contemporary, art, painting and everyday life of these young people.

Key words: Painting Mural; Education in Visual Arts; Everyday.

\section{Primeiras palavras}

O presente artigo originou-se da pesquisa de Conclusão de Curso de Licenciatura em Artes Visuais, da Universidade Federal de Santa Maria, com a colaboração de cinco adolescentes $^{3}$, participantes da Escola Aberta $^{4}$ da Escola Estadual de Educação Básica Augusto Ruschi, na área urbana de Santa Maria/RS.

A definição da temática para a pesquisa priorizou a abordagem da pintura por acreditar nas possibilidades que dispõe como flexibilizadora de diálogo educacional em artes, levando em consideração suas contribuições nas abordagens pedagógicas, por estar inserida na história, representando o contexto social de cada período.

Procurou-se relacionar as possíveis proposições educativas que pudessem ser problematizadas com a educação, por meio da pintura mural, ao envolver jovens de onze

\footnotetext{
${ }^{1}$ Artigo produzido a partir da pesquisa "Arte mural: um estudo com participantes do projeto 'Escola Aberta' da Escola Estadual de Educação Básica Augusto Ruschi", sendo que a referida pesquisa serviu de base para o trabalho de conclusão de curso em Artes Visuais - Licenciatura Plena em Desenho e Plástica sob orientação da Profa. Ms. Viviane Diehl.

2 Graduada em Artes Visuais - Licenciatura em Desenho e Plástica, pela Universidade Federal de Santa Maria (2010), atuando principalmente nos seguintes temas: cultura, arte pública e educação das artes visuais. Possui Pós-graduação em Gestão Escolar pela Universidade Cidade de São Paulo (2012). Professora de Artes da rede Municipal de Agudo (RS). Mestranda em Artes Visuais - UFSM, na linha de pesquisa Arte e Cultura.

${ }^{3}$ Os nomes aqui dados aos participantes da pesquisa são fictícios.

${ }^{4} \mathrm{O}$ referido projeto desenvolve ações junto à comunidade e grupos de estudantes aos finais de semana, através de oficinas de artes, música, dança e artesanato, além disso, jogos de recreação que incentivam a prática de atividades físicas. Desta forma a escola procura uma maior aproximação do espaço educacional com a comunidade que está em seu entorno.
} 
a quinze anos, para que, juntos fosse possível construir conhecimentos sobre a linguagem.

Desta forma, para o desenvolvimento do projeto, optou-se por realizar uma oficina com aproximadamente oito encontros, onde estudamos alguns princípios da cor e da pintura; contextualizando a arte mural, assim como artistas que utilizaram e trabalharam nessa linguagem.

A abordagem qualitativa foi eleita a fim de auxiliar na produção da pesquisa e no trabalho de campo (LÜDKE 1986). Para a análise e compreensão de dados utilizou-se da observação participante, com os registros no diário de campo, com a finalidade de refletir sobre o processo educativo e a atuação docente no contexto da Escola Aberta, como espaço educativo não formal. Os registros dos encontros foram historiados no diário de campo, registrados através das imagens fotografadas e de vídeos a fim de auxiliarem na reflexão do percurso, contextualização e compreensão dos achados da pesquisa.

O projeto de arte mural veio ao encontro dessas proposições, pois não se objetivou somente fazer uma pintura no muro da escola, mas trabalhar a arte mural como um dispositivo para articulação de diálogos que fossem relevantes nas propostas apresentadas para este estudo, a partir das temáticas trazidas pelos educandos e pela educadora, que fomentaram entrecruzamentos com as questões do cotidiano e as propostas levadas pela educadora que resultaram no tema de pesquisa.

\section{Tramando laços entre a Educação das Artes Visuais com o contexto em estudo}

é preciso perceber e analisar de que maneira as inter-relações artísticas e estéticas vêm ocorrendo ao logo do processo históricosocial da humanidade. Além disso, é preciso verificar como tais relações culturais mobilizam valores, concepções de mundo, de ser humano, de gosto e de grupos sociais. (FERRAZ e FUZARI, 2004, p. 18)

A educação das artes visuais é propositora desses estudos com os jovens, ao possibilitar reflexões e interpretações referentes as suas culturas e posturas enquanto sujeitos que integram e interagem nos grupos sociais, problematizando essas relações e criando tessituras entre as imagens que se fazem presentes no cotidiano. Contextualizando valores, crenças e estereótipos, trazendo novas indagações para o ambiente escolar, contribuindo para a produção de cultura, por meio dos saberes que cada indivíduo carrega consigo, que podem ser mediados pelos educadores, ao definir o que é importante para o estudo da arte educação e da vida, gestando valores sociais e individuais, que estão presentes na cultura e na vida dos jovens. Pode ainda desenvolver relações de inserção, de compartilhamento do conhecimento, através da flexibilidade e da união entre educadores e educandos, quando é respeitada e valorizada a cultura de cada um, de maneira que uma possa contribuir com a outra. 
Hernández descreve a importância das abordagens que podem ser articuladas entre a educação e a cultura visual, para a produção de conhecimento:

(...) um primeiro objetivo de uma educação para a compreensão da cultura visual, que, além disso, estaria presente em todas as áreas do currículo, seria explorar as representações que os individuos, segundo suas características sociais, culturais e históricas constroem da realidade. Trata-se de compreender as próprias representações. Isso significa que, diante da cultura visual, não há receptores nem leitores, mas construtores e intérpretes na medida em que a apropriação não é passiva nem dependente, mas interativa e de acordo com as experiências que cada indivíduo tenha experimentado fora da escola. Daí a importância, a posição de ponte que a cultura visual exerce: como campo de saberes que permite conectar e relacionar para compreender e aprender, para transferir o universo visual de fora da escola (do aparelho de vídeo, dos videoclipes, das capas de CD, da publicidade, até a moda e o ciberespaço etc.) com a aprendizagem de estratégias para decodificá-lo, interpretá-lo e transformá-lo na escola (HERNÁNDEZ, 2000, p. 52)

Estas possíveis contribuições da cultura visual traçam relações sociais que podem ser tecidas pela educação. Como também, envolvem as representações sociais de identidade e formas de subjetividade, ligando seus significados culturais e histórias de vida. Faz com que educadores reflitam e conheçam os diferentes contextos onde trabalham e pesquisem sobre a pedagogia cultural de seus educandos, possibilitando conexões entre as imagens e os contextos sociais, que facultam a inserção na educação como mediadora de valores e escolhas que se entrecruzam com os jovens, sejam elas da arte erudita, popular, da mídia e do cotidiano escolar e local. Decodificando-os em possíveis dispositivos para relacioná-los com os conteúdos escolares e com a arte, com os conhecimentos visuais, as informações que eles proporcionam e como são vistos.

$\mathrm{Na}$ busca, pela produção de sentidos que são subjetivos, por estarem interligados as interpretações dos sujeitos que as decifram, todavia, eles não são algo definido, mas falam pelo contexto em que se apresentam como argumenta Martins: "pelas imagens mudarem de significado quando muda o entorno ou contexto em que são veiculadas" (2007, p. 28). Desta forma, podem ser trabalhadas como alternativas que promovam a inserção de problematizações e diálogos acerca das imagens e de temáticas que a partir delas podem ser abordadas. Por isso da relevância de sua seleção e mediação por parte do professor como aponta Mirzoeff "a cultura visual, dentro desse contexto, tem a função de questionar, dialogar e mediar a seleção dessas imagens" (MIRZOEFF In: CUNHA, 2010, p. 138).

Pensando na oficina de arte mural, nas imagens que pudessem ser selecionadas para os estudos da pintura, foram eleitas, tanto gravuras da arte erudita, da televisão, internet, que possuíam relação com os estudos propostos pela oficina e pudessem ser vinculadas as possíveis abordagens e compreensões produzidas pelos participantes. Ponderando as 
formas de articulá-las a fim de que, ao mesmo tempo em que não fugisse do foco do projeto da oficina, contribuíssem para a criação de conhecimento e também como propositora de reflexão deste universo imagético que se faz presente diariamente através da mídia. Que segundo Cunha,

[...] notava que os bens de consumo, com seus padrões visuais estabelecidos e disseminados pelas grandes indústrias, sejam elas de entretenimento, moda, alimentação, brinquedos ou de móveis mantinham uma uniformização estética que impossibilitava sermos singulares (2010, p.133).

Na qual, muitas vezes nos sujeitamos à lógica do consumo, sem, no entanto, em muitas dessas situações, indagarmos sobre o que nos é oferecido. A arte contemporânea questiona essa realidade, ao estabelecer conexões com a vida, a qual é interpretada de várias maneiras pelos artistas, possibilitando uma relação com a sociedade e a realidade, problematizando temas políticos, econômicos e sociais, como trata Canton, os

[...] artistas contemporâneos buscam sentido. Um sentido que pode estar alicerçado em preocupações formais - intrínsecas à arte e que se sofisticaram com o desenvolvimento dos projetos modernistas do século $X X$-, mas que finca seus valores na compreensão (e na apreensão) da realidade, infiltrada nos meandros das políticas, da economia, da ecologia, da educação, da cultura, da fantasia, da afetividade... Em vez de uma arte per se, potente em si mesma, capaz de transcender os limites da realidade, a arte contemporânea penetra as questões cotidianas, espelhando e refletindo exatamente aquilo que diz respeito à vida. (CANTON, 2009, p.35)

A educação em artes, através dos estudos da cultura visual, pode também interagir com essas realidades que fazem parte das vivências dos educandos, ao permitir questionamentos e investigações da realidade e da sociedade no ambiente escolar que são propulsoras de variados sentidos. Uma vez que, nos deparamos com diferentes subjetividades, interesses, realidades sociais, diversidade de motivações e objetivos os quais são apresentados pelos jovens.

Pois cada indivíduo carrega consigo sua história de vida, formação que o diferencia dos outros, assim como, as sociedades se caracterizam por seus costumes e tradições, não havendo uma igualdade, mas sim formação de identidades fragmentadas (HALL, 2005), que são frutos da sociedade, isto é, da pós-modernidade e suas transformações, sejam elas, a industrialização, a globalização, as mídias internacionais.

Diante deste campo perspectivo, procurou-se encadear o contexto dos colaboradores, suas representações pessoais a educação das artes visuais para juntos criarmos o projeto para a "arte mural". Não cabendo a educadora impor uma interpretação dessas imagens, mas aguçar o interesse deles para possíveis abordagens, através de 
questionamentos, indagações, relações entre as imagens, que suscitassem o interesse do grupo pelas obras analisadas para que assim produzissem narrativas individuais, que agrupadas, fomentassem uma visão mais reflexiva. "Possibilitando um novo olhar para com a imagem e assim um novo olhar para si próprio em relação a ela e a si" (HERNANDEZ, 2007, p.31), ressignificando o olhar e reinterpretando o entorno, que vai além do ver, buscando um olhar crítico, diante de si e das coisas que se fazem presentes em seu cotidiano. Tentando romper com o imediatismo, propondo algo que instigue constantemente a curiosidade diante da vida e da escola, dos conteúdos que lhes são problematizados pelos educadores, não como simples consumidores, mas como agentes do conhecimento, uma vez que a arte pode abrir caminhos para essa nova visão do mundo, na medida em que ela é "representação do mundo cultural com significado, imaginação; é interpretação, é conhecimento do mundo; é, também, expressão de sentimentos, de energia interna, da efusão que se expressa, que se manifesta, que se simboliza" (FUSARI e RERRAZ, 2004, p. 23).

Pensando nessas interligações que no decorrer do percurso, buscou-se relacionar as temáticas trazidas pelos estudantes com imagens da arte e midiáticas, objetivando interligar os conteúdos com a vida dos educandos, com os acontecimentos visuais, as informações que eles proporcionam e como são vistos.

Contudo, deve-se levar em conta que os conhecimentos não são construídos isoladamente, uma vez que os sujeitos se constroem em relação com os outros sujeitos. Sendo que os saberes não devem ser pensados como algo acabado, mas em constante processo de formação e transformação, ir e vir, assim como nas obras dos artistas contemporâneos, onde "os sentidos, na obra dos artistas contemporâneos, não estão prontos, mas se configuram nos acontecimentos, isto é, na construção das múltiplas relações que acontecem entre a obra e o observador" (CANTON, 2009, p.51), interagindo com o mundo e suas mudanças, promovendo no ambiente escolar constantes reflexões dialógicas com a sociedade e a contemporaneidade, que estão em contínuo processo de transformação.

\section{Revisitando o percurso}

Ao pensar nessas proposições, e dar início as atividades da oficina, assim como, a organização das propostas, em um primeiro momento objetivou-se conhecer um pouco da cultura do grupo, seus conhecimentos referente à arte e sua realidade, pois como aponta Bauman, o lugar onde vivemos e as pessoas com quem convivemos fazem parte de um grupo, onde são mantidas relações, sejam elas, de compartilhamento, que no entendimento do autor nem sempre são fáceis de serem mantidas, pois, 
no local de trabalho, na vizinhança e na rua, misturamo-nos diariamente com pessoas que, como assinala Rychen, "não falam necessariamente a mesma língua (literal ou metaforicamente) nem compartilham a mesma memória ou história". Nessas circunstâncias, a habilidade de que mais necessitamos para oferecer à esfera pública alguma chance de ressuscitação é a da interação com os outros - de manter um diálogo, de negociar, de obter a compreensão mútua e de administrar ou resolver os inevitáveis conflitos em qualquer instância da vida compartilhada (2005, p. 163).

A escola, onde se deu a pesquisa, sinaliza essa interação por estar inserida em uma comunidade na periferia da área urbana de Santa Maria, e por ter como ponto de destaque a relação que mantém com as pessoas que vivem no entorno por meio da Escola Aberta, através de projetos para os quais a comunidade é convidada a participar, seja do bairro local ou arredores. Os cinco participantes da oficina de Arte Mural são exemplo de realidades distintas, que mesmo morando próximo só vieram a interagir com a oficina. Com idade entre onze e quinze anos, sendo dois estudantes do colégio, Ylda, de doze anos, aluna da $6^{\mathrm{a}}$ série e o Lucio, de 11 anos, educando da $5^{\mathrm{a}}$ série. Os outros três estudam em outras escolas da cidade, Pedro, de quinze anos, freqüenta o $1^{\circ}$ ano do Ensino Médio, já Barbara, de treze anos, estuda na $8^{a}$ série e Danilo, de onze anos, é educando da $6^{a}$ série. Os dois primeiros já participavam de oficinas na Escola Aberta e os outros tiveram o primeiro contato com o projeto durante a oficina de pintura mural.

No decorrer dos encontros os adolescentes demonstraram diferentes interesses, subjetividades, e motivações em relação ao cotidiano escolar e social, o que se observou por suas atitudes e conversas. Apesar das distinções, posições e envolvimento em relação à oficina e as temáticas abordada nos encontros, foi possível constatar a troca de conhecimentos durante o processo percorrido através das falas, das contextualizações e da pintura do mural.

As subjetividades entre os jovens não é uma peculiaridade desse grupo, mas faz parte da sociedade em geral, por estarem inseridas no processo de identidades cambiantes, isto é, em constante processo de formação e transformação, como fruto da sociedade da modernidade tardia. As quais "são caracterizadas pelas 'diferenças'; que são atravessadas por diferentes divisões e antagonismos sociais que produzem uma variedade de 'diferentes posições de sujeito'" (HALL, 2005, p.17). Nesse sentido podemos perceber as distintas identidades no contexto escolar, pois cada indivíduo carrega consigo sua história de vida, formação, costumes e tradições que o particulariza dos demais.

Através dessa perspectiva, foram pesquisadas alternativas que levassem a construção de um diálogo em conjunto para a produção de conhecimento educacional. E assim, desenvolver com estes jovens da periferia da cidade um projeto que proporcionasse reflexões a respeito de sua realidade, seus interesses e subjetividades que conjugasse 
seus anseios frente a uma sociedade que vive correndo contra o tempo, onde tudo é transitório e efêmero (NETO, 2005). Problematizando diferentes temas que fazem parte de suas vidas e que nem sempre podem ser expressados, seja por timidez ou muitas vezes pelo sistema escolar que não permite que os estudantes se manifestem. Nesse sentido Coelho descreve que:

Os sujeitos, hoje, chegam à escola com conhecimentos que desafiam narrativas tradicionais, baseadas na transmissão dos conteúdos e na autoridade do professor ou professora. Desde o início da escolarização, demonstram possuir conhecimentos e questionamentos sobre diversos temas da vida adulta, política e social, como versões das mídias sobre o ser e sobre o sentir. Os sujeitos infantis chegam à escola já possuidores de uma bagagem de vivências e de prazer com narrativas visuais, sonoras e corporais da cultura popular do seu cotidiano (COELHO, 2010, p.120).

Partindo destas premissas a oficina de arte mural propôs uma relação dialógica, tendo presente a possibilidade de conversar sobre temas do cotidiano, da abordagem de alguns princípios estéticos, ao introduzir alguns conhecimentos básicos relativos à cor, a pintura, a arte, a arte mural, a composição dos projetos, espaços em grande dimensões, o trabalho em equipe e a experiência corporal de sentir e ver a pintura ganhando forma.

Nos primeiros encontros, quando demos início as aulas de cor, formas, composição e interpretação de imagens, os educandos demonstraram algumas informações "limitadas", como podemos perceber pela fala do educando Pedro "aprendi sobre as cores primárias e secundárias lendo nas caixinhas de tinta guache", que também foi o único que se manifestou sobre as imagens das obras apresentadas "lembro da obra a árvore do Mondrian, porque já fiz um trabalho de artes, na sétima série, lá na escola, em que pesquisei sobre as obras e a vida dele e depois fiz um desenho geométrico para entregar para a professora" (PEDRO).

Ao questioná-los sobre o que aprendiam nas aulas de artes, a resposta foi que desenhavam, pintavam e aprendiam a fazer colagem, não estudavam nenhum artista, ou a história da arte e a arte contemporânea, com exceção de Pedro que citou alguns trabalhos produzidos por ele a partir da interpretação das obras de alguns artistas a pedido da professora e alguns trabalhos referentes à biografia de artistas e movimentos da arte moderna.

As respostas dos participantes em relação às cores vêm ao encontro das reflexões abordadas por Fuzari e Ferraz (2004), quando apresentam que os professores precisam rever o que estão levando para as aulas de artes, pois ao trabalhar pintura com nossos educandos, podem instigá-los a problematizar as possíveis relações consigo mesmo e com o cotidiano, assim como com as imagens que vivenciam, os fazendo perceber a presença da cor no seu dia a dia. 


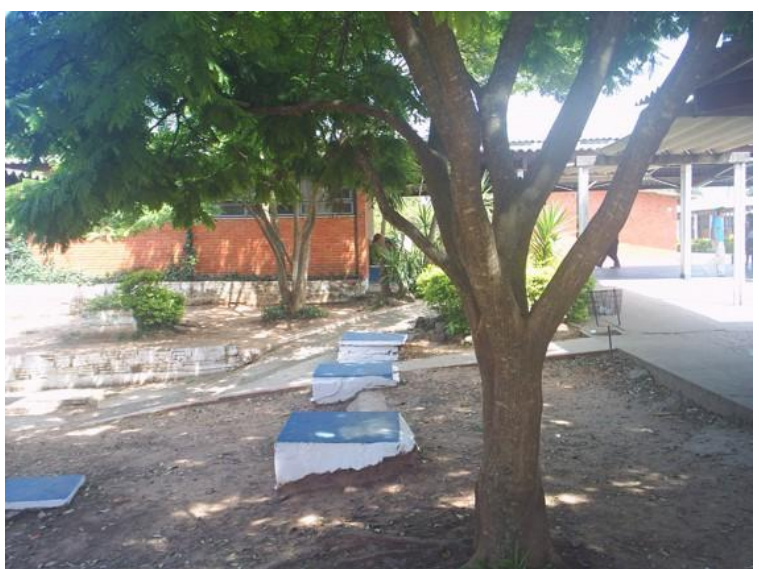

\section{Figura 01. Imagem do pátio da Escola Augusto Ruschi \\ (Imagem do arquivo pessoal da Pesquisadora).}

Para estes entrecruzamentos, procurou-se interligar o contexto dos jovens, suas representações pessoais, a fim de problematizar cruzamentos que os faziam rever "préconceitos". Opiniões prontas que, muitas vezes, são transmitidas, como algo definitivo, sem qualquer tipo de questionamentos.

Para a escolha do tema do mural, a partir das temáticas do cotidiano, foi proposto aos estudantes que pensassem em um assunto que estivesse relacionado ao seu dia a dia e que fosse do interesse deles, como podemos observar na fala de Ylda:

Pensei em alguma coisa que tenha a ver com a escola, beija flor, meio ambiente que tenha a ver com a gente. Pois todos os anos fazemos em média três caminhadas ecológicas em defesa do meio ambiente. Na terceira série, a professora criou um projeto de recolher o lixo, selecionar e eu continuo até hoje, separando o lixo. A água da máquina de lavar é reutilizada para limpar a calçada, o banheiro, molhar as flores. Pensei no meio ambiente.

Esta primeira fala sugere uma temática importante, fruto de uma experiência proporcionada durante os primeiros anos escolares, marcando sua vida, pela relação e mediação oferecida pela professora que problematizou o fazer pedagógico com a interpretação e conhecimento do mundo (FUSARI e FERRAZ, 2004).

Outros temas também foram tratados dentro desse mesmo enfoque, das relações feitas através de temáticas estudadas anteriormente, em outros momentos escolares, como o nazismo; os preconceitos sociais, especialmente de classe, entre colegas, estudantes e professores, a partir do qual foi possível adentramos no tema do bullying ${ }^{5}$, que tem movido muitas reflexões na sociedade de modo geral. Nas escolas, é mais presente através de apelidos, de agressões em forma de xingamento, que muitas vezes passam

\footnotetext{
${ }^{5}$ Compreende todas as formas de atitudes agressivas, intencionais e repetidas, que ocorrem sem motivação evidente, adotadas por um ou mais estudantes contra outro(s), causando dor e angústia, e executadas dentro de uma relação desigual de poder (In. Brasil Escola, disponível em < http://www.brasilescola.com/sociologia/bullying.htm $>$. Acessado em 20 mai. 2010).
} 
despercebidos, mas foram relatados pelos colaboradores da oficina como algo corriqueiro no ambiente das escolas. Comentaram, também, da falta de atitude dos professores frente a essas situações, que segundo eles acontece dentro das salas de aula, não com agressões físicas diretas, mas através de palavras e gestos, que podem considerar certas situações como "normais", sem atenção para o que acontece no entorno, nas atitudes de nossos jovens, ou mesmo na forma como os profissionais em educação se posicionam diante deles. Além de trazerem a tona estes temas os adolescentes também cobram a falta de atitudes da escola, dos professores, que, segundo eles, em muitos casos acabam se omitindo diante dessas situações.

A educação nesse percurso requer dos seres que fazem parte do ensino, que estejam abertos aos conhecimentos do outro, ao que eles trazem consigo. Contudo, nem sempre essas articulações são fáceis de serem mediadas, e para que esse processo seja relevante é importante que ele possa ser construído por meio de constantes "medições", analises e reavaliações, para se ter um alicerce sólido.

Com o objetivo de criar diálogos entre a arte, a educação e os conhecimentos dos colaboradores da pesquisa, oportunizou-se a eles a possibilidade de escolher a temática que consideravam mais relacionada ao contexto de todos. Dentre as já citadas anteriormente, optaram pelo meio ambiente, por alegarem que faz parte da vida de todos, como é argumentado por Barbara que diz: "Pensei na poluição, no meio ambiente, lá em casa a gente recicla o lixo orgânico para adubar a horta e as pessoas querem ajudar na preservação do meio ambiente, mas não sabem como". Também apresentaram outras justificativas, considerando este ser um problema mundial e que todos precisam estar conscientes e para tanto as escolas devem abordá-106.

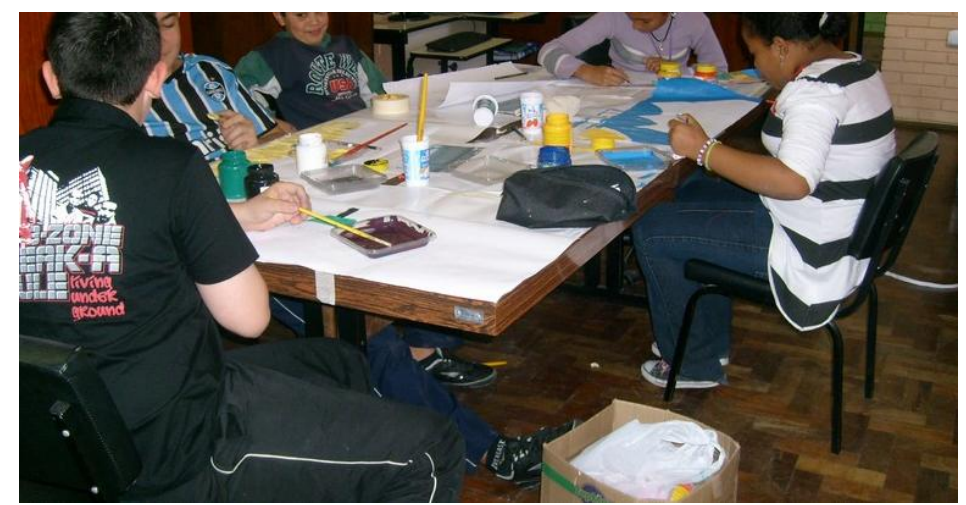

Figura 02. Imagem dos colaboradores realizando os primeiros trabalhos práticos na oficina.

(Imagem do arquivo pessoal da Pesquisadora).

\footnotetext{
${ }^{6}$ No caso específico do nome da escola ela se constitui numa homenagem ao naturalista Augusto Ruschi (19151986), defensor do meio ambiente.
} 
A partir da definição do tema, o grupo deu início a produção dos projetos, através de imagens de pinturas murais, da mídia, gerando conversas sobre as composições, processos e as temáticas estudadas. Ao final da produção dos trabalhos, retomamos as discussões dos primeiros encontros e as produções dos projetos, pois como delineia Martins (2009), cabe ao educador problematizar reflexões sobre o processo educacional com seus educandos, não simplesmente oferecer soluções prontas, e apresentar no mural, a temática do meio ambiente e de alguma forma a importância de preservá-lo.

A partir de tal premissa, conversamos sobre as imagens estereotipadas que estiveram presentes nos primeiros esboços dos projetos e como eles poderiam fazer as alterações necessárias, sem deixar de destacar os pontos positivos de cada um dos trabalhos realizados pelos educandos. Bem como das imagens que poderiam fazer parte do projeto final. Após os diálogos, os participantes decidiram criar um projeto em grupo. Para tanto, resolvemos pegar partes dos projetos já criados por eles, articulando com imagens que representavam a preservação do meio ambiente e o símbolo da escola. Após as contextualizações, o projeto coletivo foi organizado.

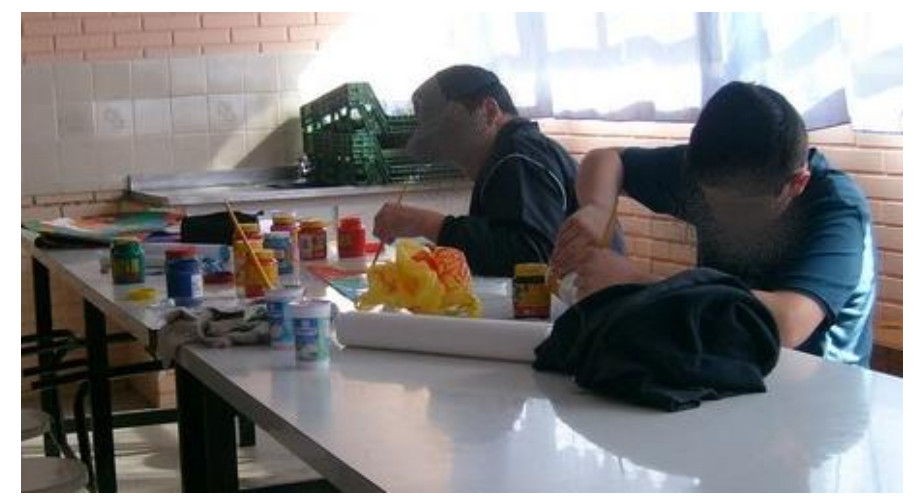

Figuras 03. Produção do projeto final para a intervenção no muro (Imagens do arquivo pessoal da pesquisadora)

Como parte do trabalho, antes de passar o projeto para o muro da escola, foi necessário fazer a limpeza do mesmo, pois ao lado fica a lixeira da escola e naquele dia um cachorro da redondeza passou pelo local e arrebentou os sacos que haviam sido colocados ali para serem recolhidos pelo caminhão de lixo, espalhando tudo em frente à parede que iria ser pintada. A limpeza do pátio suscitou problematizações e relações com a temática escolhida. Pois não basta apenas

incorporar uma visão crítica, que questiona toda forma de pensamento único, a fim de que os alunos entendam que as produções artísticas e suas interpretações não são inocentes e objetivas, mas interessadas, e que estão amparadas em realidades que acolhem e veiculam diferentes visões de mundo (FERREIRA, 2004, p. 16). 
Além de críticos, precisamos ter atitudes e decisões concretas diante de certas situações, sejam elas simples ou complexas, pois não basta somente questionar, temos que fazer. E a partir de atitudes concretas contribuindo com críticas reflexivas, seja por meio da arte ou da educação.

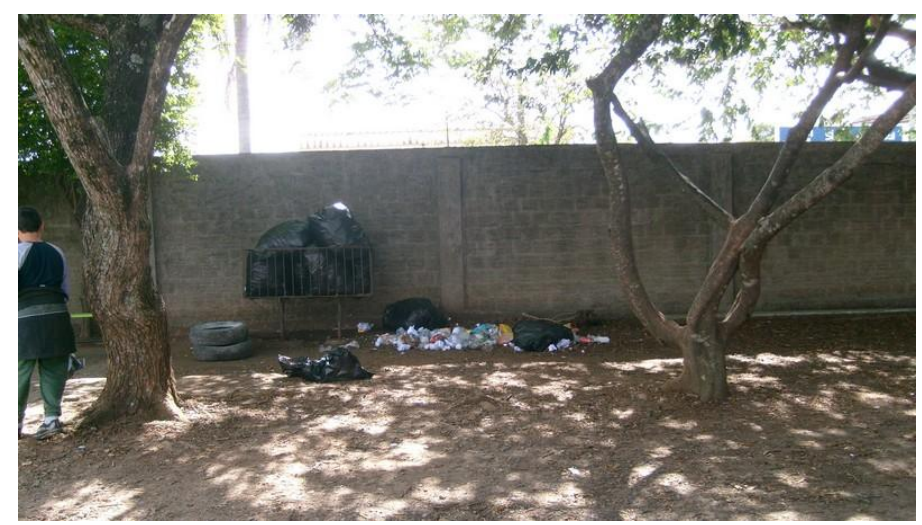

Figuras 04. O muro da escola antes de darmos início a pintura.

(Imagens do arquivo pessoal da pesquisadora)

Após a limpeza, de posse dos materiais para a pintura e com o projeto em mãos, demos início aos desenhos no muro. Já nos primeiros esboços percebemos a dificuldade que teríamos para pintá-lo, por ser muito áspero, a tinta não cobria as irregularidades do reboco, e por isso tivemos que dar três demãos de tinta em cada parte. Levamos mais de duas horas para pintar o fundo azul em torno da representação do sol, que não ficou pronto naquele encontro.

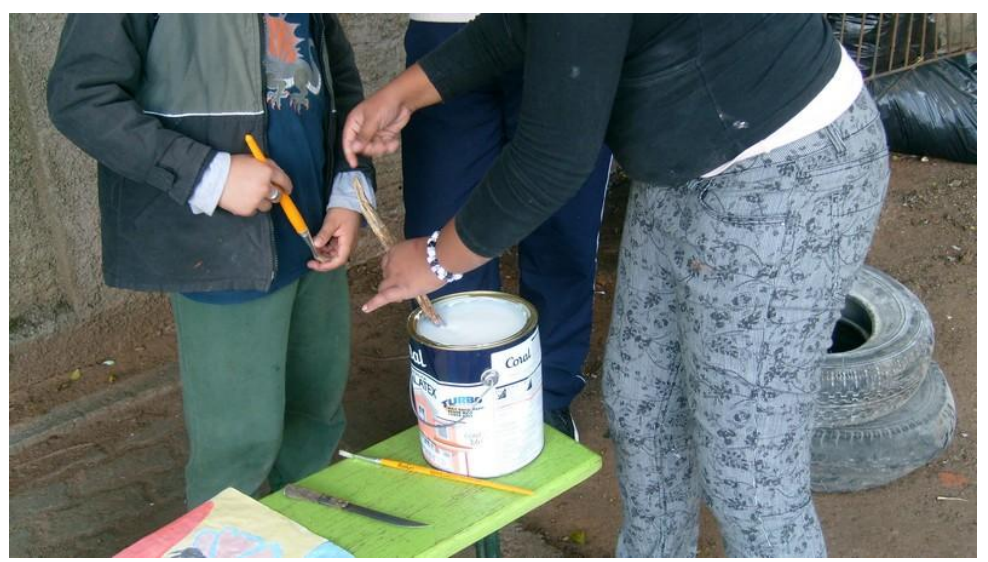

Figuras 05. Preparando os materiais e o espaço para dar início a pintura no muro da escola.

(Imagem do arquivo pessoal da pesquisadora) 


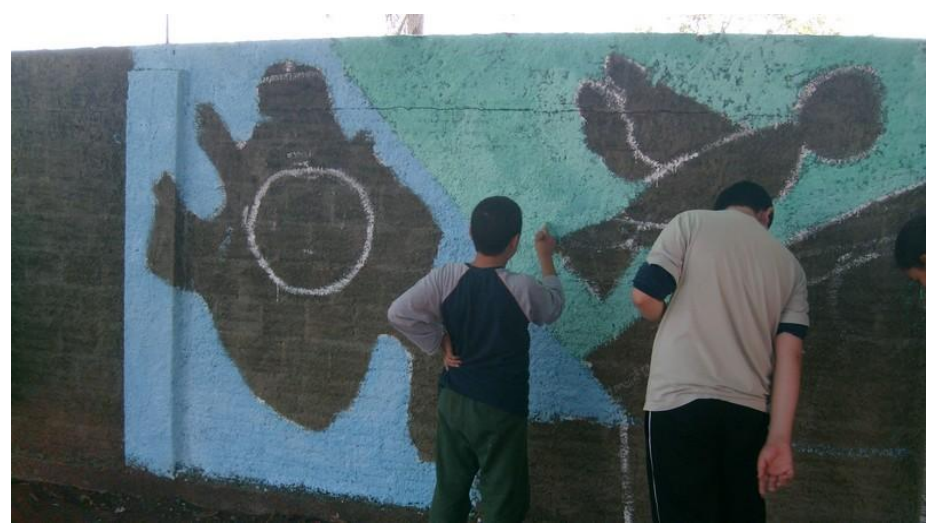

\section{Figura 06. Participantes do projeto pintando o mural (Imagem do arquivo pessoal da pesquisadora)}

O trabalho foi intenso, mas as conversas, as brincadeiras entre os participantes da oficina amenizaram as dificuldades (levamos dois encontros, em turno integral, de oito horas para concluir a pintura). Durante o trabalho prático aproveitamos para conversar sobre nossas vidas, arte, escola, disciplinas e professores. O grupo contou um pouco sobre suas famílias, irmãos, me perguntaram sobre a faculdade, os ateliês, a pintura, porque eu havia escolhido o curso de artes, dentre tantos outros. Retomamos algumas discussões referentes às cores, as misturas, as quantidades de corante para dar as tonalidades desejadas. Para fazer o azul da figura humana, mais acinzentada, Ylda perguntou como se fazia. E Lucio prontamente respondeu para ela: "hora, é só colocar um pouco de corante preto com a tinta branca e o corante azul, mas pouco".

Paralelamente aproveitamos para retomar as ideias, procurando interligar os conhecimentos produzidos na oficina com as subjetividades dos educandos, a fim de que percebessem as relações que foram sendo estabelecidas entre as temáticas propostas. Tramando laços não só educacionais, mas afetivos que vão além das relações tradicionais de professor e aluno, vínculos importantes à formação pessoal e educacional (FIGUEIREDO, 2009).

Produzindo cultura, por meio dos símbolos, da interação entre os indivíduos, dos conhecimentos que cada um possui, das imagens estudadas e as produzidas por eles (HÉRNANDEZ, 2006) que foram tecidos no decorrer dos encontros. 


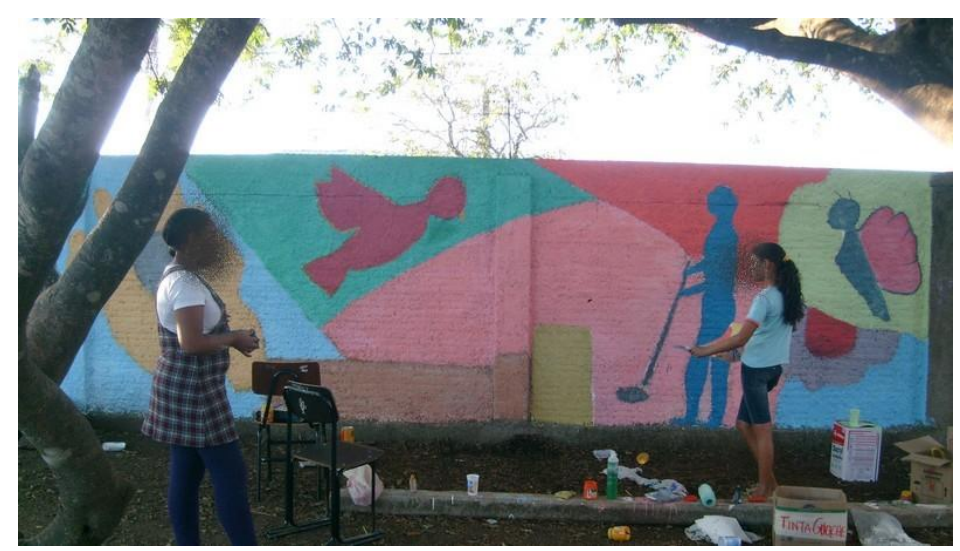

Figuras 07. Participantes do projeto pintando o mural (Imagem do arquivo pessoal da pesquisadora)

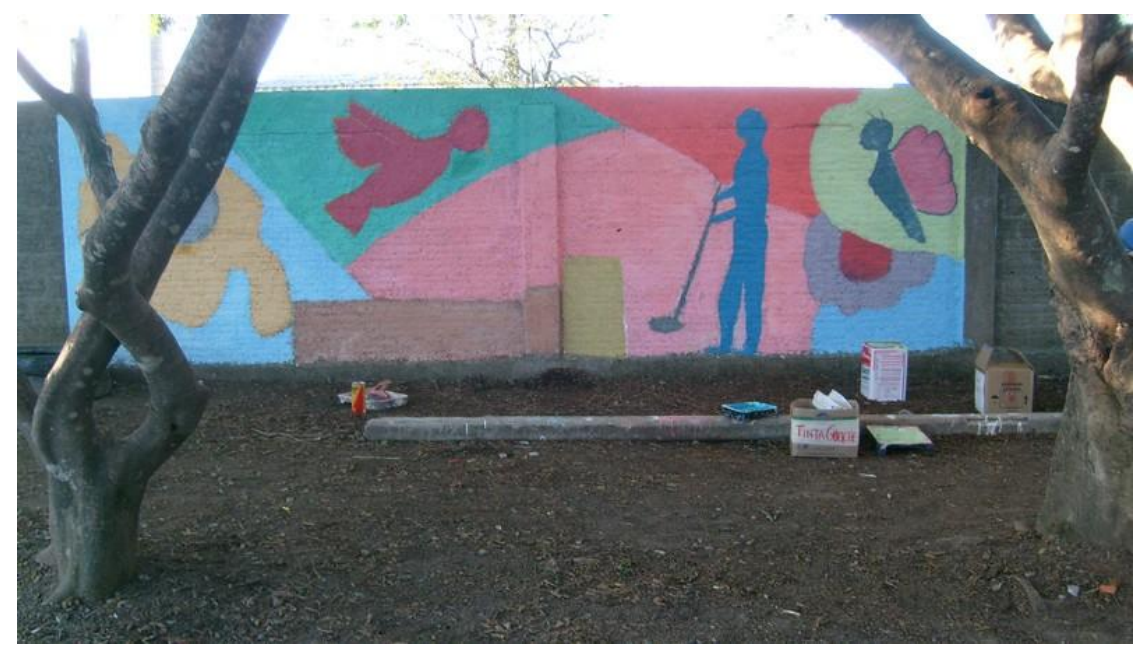

Figura 08. Mural pintado pelos colaboradores do projeto (Imagens do arquivo pessoal da pesquisadora)

Ao final da pintura, nos encontramos para conversarmos sobre o processo, o tema proposto e mais especificamente, a experiência de participar da oficina. Os jovens, neste encontro falaram mais do conhecimento produzido nos encontros, como podemos observar na fala de Lucio: "Tu não pode parar com a oficina, é legal. A gente aprende muita coisa. Se tu parar agora, não volta mais. Mesmo com os desentendimentos, eu adorei participar da oficina"; de Danilo: "Aprendi muitas coisas sobre arte, artistas famosos e interpretação de imagens. Também aprendi mais sobre trabalho de equipe que eu não era muito... eu gostaria de ir de novo a mais uma oficina". E de Ylda: "tenho dois quadros no meu quarto, mas nem sabia quem tinha pintado. Daí, depois que eu comecei a oficina, eu pesquisei... eu comecei a me interessar mais por arte, a oficina é muito legal, interessante".

Procurando, dessa forma, valorizar o que Ihes é próprio, como propugnou Hall (2005), suas raízes identitárias, suscitando reflexões e trocas de relações durante a caminhada, colaborando na problematização e na construção da proposta, articulando conexões com a vida dos educandos. O que foi possibilitado pela educação de artes visuais e das inter- 
relações mediadas com o contexto destes jovens, os fazendo pensar e analisar suas culturas, valores e posições enquanto grupos sociais e sujeitos que interagem entre si. Haja vista que a arte contemporânea tece ligações entre a arte e a processo cultural atual. Onde, por meio da arte contemporanea se procurou tecer ligações com as vivencias de cada colaborador da pesquisa. Que se deu por meio dos relatos produzidos por eles, dos trabalhos plásticos confeccionados, que foram inter-ligadas as propostas educativas de artes durante os encontros da oficina.

\section{A vida passa, mas nossa memória guarda lembranças}

Este trabalho teve como objetivo abordar as possibilidades da pintura em arte mural, numa proposição educativa em artes que almejou integrar o cotidiano dos participantes com os conteúdos de artes. Tecendo relações com a educação na contemporaneidade, com a arte e a pintura, suas confluências com o processo de formação de identidade, por meio da cultura visual, de temas do cotidiano e das subjetividades de cada participante. Desse modo, aproximando problematizações no tocante a arte, a pintura mural e a educação, através de alguns estudiosos e artistas que dialogaram com as temáticas estudadas.

No processo de análise das propostas desenvolvidas na oficina, foi decidido por uma abordagem descritiva interpretativa, não apenas uma descrição dos fatos ocorridos linearmente, mas por um estudo das produções e relações lançadas no campo educacional. Para tanto, foi utilizado o diário de campo, os vídeos criados durante os encontros, as fotografias e os materiais produzidos pelos próprios alunos, dentre eles, textos escritos, pinturas e os projetos para o mural; os quais auxiliaram na abordagem das inter-relações tramadas entre as propostas levadas pela educadora e as conjeturas produzidas pelos educandos.

Ao interagir com o grupo e o espaço enquanto limitador de passagem, por meio da pintura mural, procurou-se ter presente que o muro onde a pintura foi realizada, separa o ambiente escolar da comunidade que está em seu entorno. Uma vez que, os muros podem ter a finalidade de proteger os espaços privados, sem questionamentos, sem diálogos, somente como imposição, por uma parede que não diz nada, só separa espaços, vidas e histórias. A pintura mural permitiu que se fizessem tessituras entre essas histórias, pois por meio dela, foi possível contextualizar com a escola e com os estudantes através das reflexões produzidas, da pintura e dos diálogos com educadores sobre essa realidade; aproximando pessoas e identidades.

A oficina como um todo possibilitou aos colaboradores criarem relações entre as práticas e os temas tecidas no decorrer dos encontros, observado pelas falas e relatos produzidos por eles ao final da jornada. Além de terem se interessado por conhecer outros artistas e 
linguagens. Fizeram relações com assuntos de seu interesse. Por fim, a oficina de arte mural abriu possibilidades de desenvolver outros trabalhos com o grupo, permitindo também a outros adolescentes da comunidade a virem se interessar e solicitar para participar dos encontros.

\section{Referências:}

BAUMAN, Zygmunt. Vida Liquida. Rio de Janeiro: Jorge Zahar, 2005.

CANTON, Katia. Narrativas Enviesadas. São Paulo: Martins Fontes, 2009.

COELHO, Roseane Martins. O sujeito e a construção da identidade: implicações na infância, na educação e na arte. In: MARTINS, Raimundo; TOURINHO, Irene (orgs.). Cultura Visual e Infância: quando as imagens invadem a escola... Santa Maria: Editora UFSM, 2010, p. 105-130.

CUNHA, Susana Rangel Vieira da. As infâncias nas tramas da cultura visual. In: MARTINS, Raimundo; TOURINHO, Irene (orgs.). Cultura Visual e Infância: quando as imagens invadem a escola... Santa Maria: Editora UFSM, 2010, p. 131- 161.

FERRAZ, Maria Heloísa C. de T. e FUZARI, F. de Rezende e. Metodologia do Ensino de Arte. São Paulo: Ed. Cortez, 2004.

FERREIRA, Sueli. O Ensino das artes construindo caminhos. 3a Ed. São Paulo: Editora Papiros, 2004.

FIGUEIREDO, João. Educação e afetividade na relação com @ outr@: contributos da perspectiva eco-relacional. In: HENZ, Celso Ilgo; ROSSATO, Ricardo; BARCELOS, Valdo. Educação humanizadora e os desafios da diversidade. Santa Cruz do Sul: UDUNISC, 2009, p. 21-43.

HALL, Stuart. A identidade cultural na pós-modernidade. 10 ed. Rio de Janeiro: DP\&A, 2005.

HERNANDEZ, Fernando. Catadores da cultura visual: transformando fragmentos em nova narrativa educacional. Porto Alegre: Mediação, 2007.

Los Estúdios de Cultura Visual: La construcción permanente de un campo no disciplinar. La Puerta. Publicación de Arte y Deseño, 2006.

. Cultura visual, mudança educativa e projeto de trabalho. Porto Alegre: Artes Médicas Sul, 2000.

LÜDKE, Menga, André, Marli G. D. A. Pesquisa em educação. Abordagens qualitativas. São Paulo: EPU, 1986.

MARTINS, Raimundo. A cultura visual e a construção social da arte, da imagem a das práticas do ver. In: OLIVEIRA, Marilda Oliveira de (Org.). Arte, educação e cultura. Santa Maria: Editora UFSM, 2007.

NETO, Augusto dos Santos. A pintura como arte pública. In: MARTINS, Alice F.; COSTA, Luiz $\mathrm{E}$; MONTEIRO, Rosane $\mathrm{H}$. $\mathbf{1 4}^{\circ}$ Encontro: Cultura Visual e desafios da pesquisa em Artes. Goiânia: UFG, 2005. 